\title{
ON A MORE ACCURATE REVERSE HILBERT-TYPE INEQUALITY IN THE WHOLE PLANE
}

\author{
Michael Th. Rassias, BICHENG YANG AND ANDREI RAIgOROdSKII
}

\begin{abstract}
In the present paper, using weight coefficients and applying Hermite-Hadamard's inequality, we derive a new, more accurate reverse Hilbert-type inequality in the whole plane with multi-parameters involving the cosine and natural logarithm functions. The corresponding constant factor is proved to be the best possible. We additionally consider some equivalent forms and a few particular inequalities. As an application, the obtained results are compared with some previously known results and we show that these new results are more accurate than the earlier ones.
\end{abstract}

Mathematics subject classification (2010): 26D15, 47A05.

Keywords and phrases: Hilbert-type inequality, weight coefficient, Hermite-Hadamard's inequality, equivalent form, parameter, reverse.

\section{REFERENCES}

[1] G. H. HARDY, Note on a theorem of Hilbert concerning series of positive terms, Proceedings London Math. Soc., vol. 23, no. 2, Records of Proc. xlv-xlvi, 1925.

[2] G. H. HaRdy, J. E. LitTlewood AND G. Pólya, Inequalities, Cambridge University Press, Cambridge, 1934.

[3] B. C. YANG, The Norm of Operator and Hilbert-type Inequalities, Science Press, Beijing, China, 2009.

[4] B. C. YANG, Discrete Hilbert-type Inequalities, Bentham Science Publishers Ltd., The United Arab Emirates, 2011.

[5] Z. Q. WANG AND D. R. Guo, Introduction to Special Functions, Science Press, Beijing, China, 1979.

[6] D. S. Mitrinović, J. E. PeČArić AND A. M. Fink, Inequalities Involving Functions and their Integrals and Derivatives, Kluwer Acaremic Publishers, Boston, 1991.

[7] M. Z. GAO And B. C. YAng, On extened Hilbert's inequality, Proceedings of the American Math. Society, 1998, 126 (3): 751-759.

[8] Y. Hong, All-side generalization about Hardy-Hilbert integral inequalities, Acta Mathematica Sinica, 2001, 44 (4): 619-625.

[9] Y. HONG, B. HE, B. YANG, Necessary and sufficient conditions for the validity of Hilbert type integral inequalities with a class of quasi-homogeneous kernels and its application in operator theory, J. Math. Inequal. 12 (2018), 777-788.

[10] K. W. Zhang, A bilinear inequality, Journal of Mathematical Analysis and Applications, 2002, 271: $188-296$.

[11] A. BENYI AND C. OH, Best constant for certain multilinear integral operator, Journal of Inequalities and Applications, vol. 2006, Article ID 28582, 2006.

[12] J. C. Kuang And L. Debnath, On Hilbert's type integral inequalities on the weighted Orlicz spaces, Pacific J. Appl. Math., 2006, 1 (1): 95-104.

[13] Y. J. Li AND B. HE, On inequalities of Hilbert's type, Bulletin of the Australian Mathematical Society, 2007, 76 (1): 1-13.

[14] L. E. AzAR, On some extensions of Hardy-Hilbert's inequality and applications, Journal of Inequalities and Applications, vol. 2008, Article ID 546829, 2008. 
[15] W. Y. Zhong, The Hilbert-type integral inequality with a homogeneous kernel of Lambda-degree, Journal of Inequalities and Applications, vol. 2008, Article ID 917392, 2008.

[16] J. J. Jin AND L. DeBnAth, On a Hilbert-type linear series operator and its applications, Journal of Mathematical Analysis and Applications, 2010, 371 (2): 691-404.

[17] Q. L. HUANG, On a multiple Hilbert-type integral operator and applications, Journal of Inequalities and Applications, vol. 2010, Article ID 309319, 2010.

[18] B. C. YANG AND M. KRnIĆ, On the norm of a multi-dimensional Hilbert-type operator, Sarajevo Journal of Mathematics, 2013, 7 (20): 223-243.

[19] M. KRnIĆ AND P. VuKOVIĆ, On a multidimensional version of the Hilbert-type inequality, Analysis Mathematica, 2012, 38: 291-303.

[20] G. V. Milovanović and M. Th. Rassias (eds.), Analytic Number Theory, Approximation Theory and Special Functions, Springer, 2014.

[21] M. TH. Rassias And B. C. YAnG, On half-discrete Hilbert's inequality, Applied Mathematics and Computation, 2013, 220: 75-93.

[22] M. TH. RASSIAS AND B. C. YANG, A multidimensional half-discrete Hilbert-type inequality and the Riemann zeta function, Applied Mathematics and Computation, 2013, 225: 263-277.

[23] M. Th. RASSiAs And B. C. YANG, On a multidimensional half-discrete Hilbert-type inequality related to the hyperbolic cotangent function, Applied Mathematics and Computation, 2014, 242: 800813.

[24] M. TH. RASSIAS AND B. C. YANG, On a multidimensional Hilbert-type integral inequality associated to the gamma function, Applied Mathematics and Computation, 2014, 249: 408-418.

[25] M. TH. RASSIAS AND B. C. YANG, A Hilbert-type integral inequality in the whole plane related to the hyper geometric function and the beta function, Journal of Mathematical Analysis and Applications, 2015, 428 (2): 1286-1308.

[26] V. AdiyASUREN, Ts. BATBOLd AND M. KRnić, Half-discrete Hilbert-type inequalities with mean operators, the best constants, and applications, Appl. Math. Comput., 2014, 231: 148-159.

[27] Q. L. HuAng, A new extension of Hardy-Hilbert-type inequality, Journal of Inequalities and Applications (2015), 2015: 397.

[28] B. HE, A multiple Hilbert-type discrete inequality with a new kernel and best possible constant factor, Journal of Mathematical Analysis and Applications, 2015, 431: 990-902.

[29] Y. P. SHI AND B. C. YANG, A new Hardy-Hilbert-type inequality with multiparameters and a best possible constant factor, Journal of Inequalities and Applications (2015), 2015: 380.

[30] M. TH. RAssiAs, B. C. YANG, On a Hardy-Hilbert-type inequality with a general homogeneous kernel, Int. J. Nonlinear Anal. Appl. 2016, 7 (1): 249-269.

[31] V. Adiyasuren, Ts. Batbold, AND M. KRnić, Multiple Hilbert-type inequalities involving some differential operators, Banach J. Math. Anal., 2016, 10 (2), 320-337.

[32] M. TH. RASSiAS, B. C. YANG, A more accurate half-discrete Hardy-Hilbert-type inequality with the best possible constant factor related to the extended Riemann-Zeta function, Int. J. Nonlinear Anal. Appl., 2016, 7 (2): 1-27.

[33] M. TH. RASSIAS AND B. C. YANG, Equivalent conditions of a Hardy-type integral inequality related to the extended Riemann zeta function, Adv. Oper. Theory, 2017, 2 (3): 237-256.

[34] M. TH. RASSIAS AND B. C. YANG, Equivalent properties of a Hilbert-type integral inequality with the best constant factor related the Hurwitz zeta function, Ann. Funct. Anal., 2018, 9 (2): 282-295.

[35] M. Th. Rassias, B. C. YAng And A. Raigorodskit, Two Kinds of the Reverse Hardy-Type Integral Inequalities with the equivalent forms related to the extended Riemann zeta function, Appl. Anal. Discrete Math., 2018, 12: 273-296.

[36] M. TH. RASSIAS AND B. C. YANG, On an equivalent property of a reverse Hilbert-type integral inequality related to the extended Hurwitz-zeta function, Journal of Mathematical Inequalities, 2019, 13(2): 315-334.

[37] M. TH. RASSIAS AND B. C. YANG, A reverse Mulholland-type inequality in the whole plane with multi-parameters, Appl. Anal. Discrete Math., 2019, 13: 290-308.

[38] M. Th. RAssias, B. YANG, On a Hilbert-Type Integral InequalityRelated to the Extended Hurwitz Zeta Function in the Whole Plane, Acta Appl. Math. 160 (2019), 67-80.

[39] J. KuAnG, Applied inequalities, Shangdong Science and Technology Press, Jinan, China, 2004. 